\title{
Article \\ Experimental Studies of Low-Load Limit in a Stoichiometric Micro-Pilot Diesel Natural Gas Engine
}

\author{
Vinicius Bonfochi Vinhaes ${ }^{1}\left(0\right.$, Gordon McTaggart-Cowan ${ }^{2}\left(\mathbb{D}\right.$, Sandeep Munshi ${ }^{3}$, Mahdi Shahbakhti ${ }^{4, *(1)}$ \\ and Jeffrey D. Naber ${ }^{1}$ \\ 1 Mechanical Engineering-Engineering Mechanics, Michigan Technological University, \\ Houghton, MI 49931, USA; vbvinhae@mtu.edu (V.B.V.); jnaber@mtu.edu (J.D.N.) \\ 2 School of Sustainable Energy Engineering, Faculty of Applied Sciences, Simon Fraser University, \\ Surrey, BC V3T 0N1, Canada; gordon_mctaggart-cowan@sfu.ca \\ 3 Advanced Engineering, Westport Fuel Systems Inc., Vancouver, BC V6P 6G2, Canada; \\ Sandeep.Munshi@wfsinc.com \\ 4 Mechanical Engineering Department, University of Alberta, Edmonton, AB T6G 2R3, Canada \\ * Correspondence: mahdi@ualberta.ca
}

Citation: Bonfochi Vinhaes, V.; McTaggart-Cowan, G.; Munshi, S.; Shahbakhti, M.; Naber, J.D. Experimental Studies of Low-Load Limit in a Stoichiometric Micro-Pilot Diesel Natural Gas Engine. Energies 2022, 15, 728. https://doi.org/ $10.3390 /$ en15030728

Academic Editor: Xiangyu Meng

Received: 24 December 2021

Accepted: 17 January 2022

Published: 19 January 2022

Publisher's Note: MDPI stays neutral with regard to jurisdictional claims in published maps and institutional affiliations.

Copyright: (C) 2022 by the authors. Licensee MDPI, Basel, Switzerland. This article is an open access article distributed under the terms and conditions of the Creative Commons Attribution (CC BY) license (https:// creativecommons.org/licenses/by/ $4.0 /$ )

\begin{abstract}
While operating at light loads, diesel pilot-ignited natural gas engines with lean premixed natural gas suffer from poor combustion efficiency and high methane emissions. This work investigates the limits of low-load operation for a micro-pilot diesel natural gas engine that uses a stoichiometric mixture to enable methane and nitrogen oxide emission control. By optimizing engine hardware, operating conditions, and injection strategies, this study focused on defining the lowest achievable load while maintaining a stoichiometric equivalence ratio and with acceptable combustion stability. A multi-cylinder diesel 6.7 L engine was converted to run natural gas premix with a maximum diesel micro-pilot contribution of $10 \%$. With a base diesel compression ratio of 17.3:1, the intake manifold pressure limit was $80 \mathrm{kPa}$ (absolute). At a reduced compression ratio of $15: 1$, this limit increased to $85 \mathrm{kPa}$, raising the minimum stable load. Retarding the combustion phasing, typically used in spark-ignition engines to achieve lower loads, was also tested but found to be limited by degraded diesel ignition at later timings. Reducing the pilot injection pressure improved combustion stability, as did increasing pilot quantity at the cost of lower substitution ratios. The lean operation further reduced load but increased NOx and hydrocarbon emissions. At loads below the practical dual-fuel limit, a transition to lean diesel operation will likely be required with corresponding implications for the aftertreatment system.
\end{abstract}

Keywords: high-efficiency engine; micro-pilot diesel; natural gas; stoichiometric operation; low load

\section{Introduction}

Modern society relies on the transportation of products and people, and due to the abundant supply, convenience, and affordability of liquid fuels, transportation is virtually entirely powered by conventional internal combustion engines (ICEs). Furthermore, stationary combustion engines (i.e., generators) are essential in medical facilities, industries, and many other services [1]. Demand for high-efficiency engines with high specific power output, low greenhouse gas emissions, and ever lower pollutant emissions is expected to continue to grow [2]. Natural gas (NG) as an alternative fuel is an exciting subject of research in ICEs because of its significant potential to reduce $\mathrm{CO}_{2}$ and oxides of nitrogen (NOx) emissions [3].

Compression ignition engine types that burn two distinct fuels in different mixture quantities simultaneously are often described as dual-fuel engines. The combination of the lean-burn of a premixed NG-air mixture with a considerable quantity of diesel injection as the combustion pilot is a characteristic of the conventional dual-fuel engines [4]. Diesel-like fuel conversion efficiencies and relatively low NOx emissions have been demonstrated in 
such engines. However, system development and on-road vehicle use have been limited by low combustion efficiency, limited diesel replacement, and high unburned methane emissions [5,6]. As a result, lean-burn engines have not been able to gain a large share of the on-road vehicle market. Combining an overall stoichiometric fuel-air combination with a small diesel pilot injection ("micro-pilot") is another option. Because only a small quantity of diesel is required to ignite the premixed charge, high substitution rates are attainable. The overall stoichiometric mixture enables the use of a three-way catalyst (TWC) to obtain extremely low NOx, Carbon Monoxide (CO), and hydrocarbon emissions (which are predominantly $\mathrm{CH}_{4}$ ) [7]. At moderate- and high-load conditions, significant net fuel cost and greenhouse gas (GHG) emission reductions are feasible by keeping diesel-like compression ratios (CR) and efficiency when paired with a low-carbon fuel. At low loads, the inducted air mass needs to be reduced to maintain stoichiometric operation. This leads to low end-of-compression pressure which, when combined with near-stoichiometric premixed fuel concentrations, can impede the ignition of the diesel pilot. This imposes a fundamental limit on the feasible operating range of such a stoichiometric micro-pilot engine.

Multiple researchers have studied the performance and emissions of conventional dual-fuel operation, including the effects of intake manifold air temperature (IMAT) and manifold air pressure (MAP), substitution ratios, exhaust gas recirculation (EGR), equivalence ratio, and the effects of injection timing. Figure 1 summarizes the recent work in pilot-ignited natural gas engines that included the low-load operation regime that is the focus of the current study.

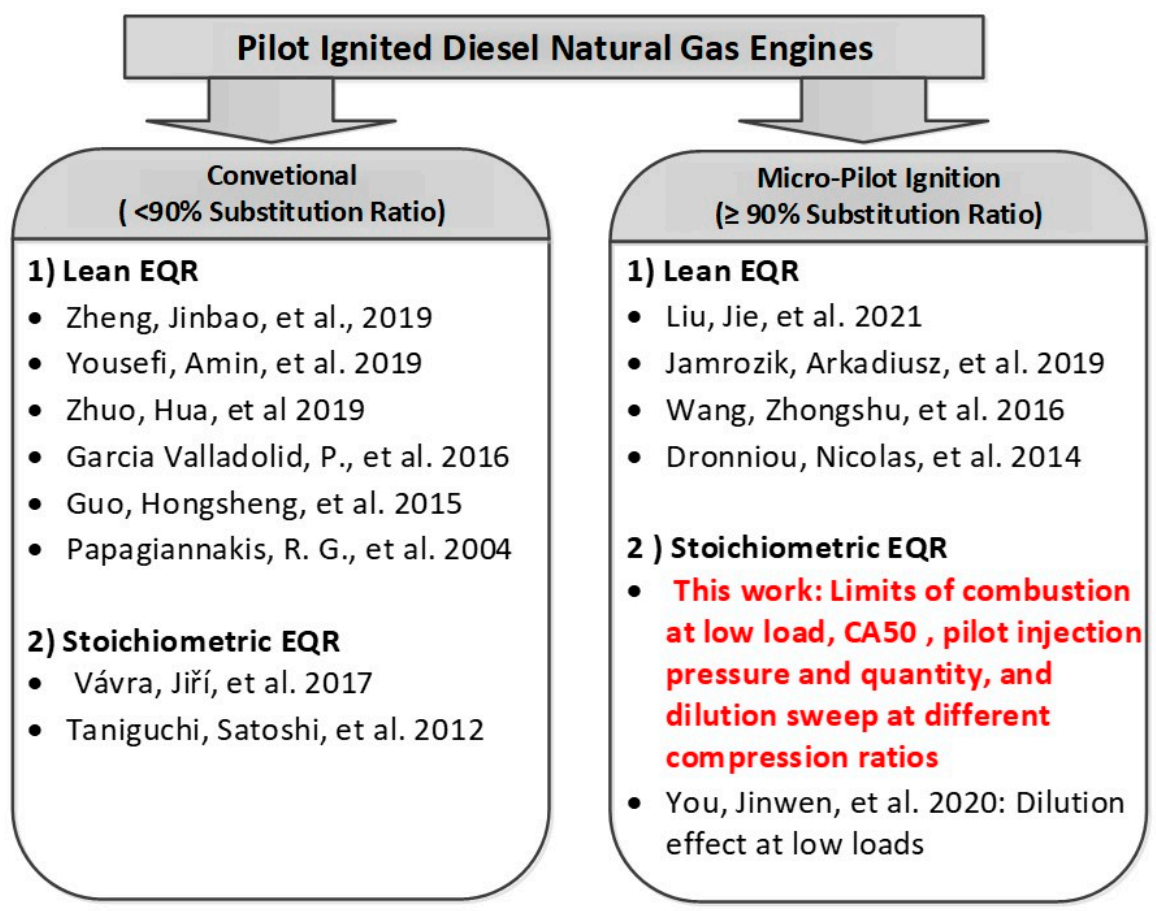

Figure 1. Recent pilot-ignited diesel natural gas engines in the low to medium load operation range research and contributions of this work compared to the state of the art [7-19]. EQR: Equivalence Ratio. CA50: Crank Angle position at which 50\% of the heat from combustion has been released.

The influence of the equivalence ratio was investigated by Zheng et al. [8]. Their research revealed that premixed lean-burn engines have a slower flame propagation, whereas increasing the equivalence ratio increases the heat release rate and exhaust gas temperature, resulting in improved thermal efficiency and reduced methane emissions. However, NOx emissions are higher if no dilution is used because of the higher temperatures. The effect of diesel pilot start of injection (SOI) was investigated by Yousefi et al. [9] and Zhou et al. [10] in a range of operating conditions varying from low to high load and 
speeds. Both researchers agree that for all the engine load-speed conditions studied, the results demonstrated that the pilot diesel SOI advance increases peak cylinder pressure, thermal efficiency, and undesirable NOx emissions increase due to higher in-cylinder temperatures driven by the higher pressure. Under the low load-low speed and medium load-high speed conditions, advancing the SOI significantly reduced unburned methane and $\mathrm{CO}_{2}$ emissions. Their findings also show that, under low load-low speed and medium load-high speed conditions, the central part of the combustion chamber is the primary source of unburned methane emissions, and advancing diesel pilot SOI significantly improves premixed mixture combustion in this region of the combustion chamber.

The study by Valladolid and Tunestal [11] shows the effect of intake manifold conditions while operating a light-duty diesel pilot natural gas engine at low loads. The results show that the IMAT plays an essential role in flame propagation under high dilution conditions and that the higher air temperature allows for the total unburnt hydrocarbon emissions to be reduced. Under high dilution conditions, throttling effectively reduces emissions and increases fuel conversion efficiency through higher combustion efficiency due to a richer premixed NG-air mixture. When the engine was operated above 5 bar indicated mean effective pressure (IMEP), it was possible to achieve unburned hydrocarbon levels below the legislated limit and with exhaust gas temperatures high enough to enable methane oxidation in the aftertreatment. Their work also suggested that the stoichiometric operation would allow a three-way catalyst usage. However, this approach introduces a penalty on $\mathrm{CO}$ emissions and thermal efficiency.

Guo, et al. [12] investigated the combustion and emissions performance of the diesel pilot natural gas engines in a range of loads and speeds varying from low to medium loads. In their work, as the natural gas substitution ratio was increased, a pilot injection timing sweep was conducted. They reported that a maximum of 50\% natural gas fraction was reached at the low-load condition, while $70 \%$ natural gas fraction was achieved in the medium load. The minimum diesel pilot pulse width was the substitution ratio limiting factor in their study. The increase in the natural gas ratio led to a retarded combustion phasing at a constant pilot injection timing, and brake thermal efficiency decreased significantly at low loads. The natural gas substitution increased methane emissions while reducing $\mathrm{CO}_{2}$ emissions. At low loads, the $\mathrm{CO}$ emissions increased due to decreased combustion efficiency. This observation is also consistent with other research $[14,15,20]$.

Poorghasemi et al. [21] employed a detailed chemical kinetics mechanism in a commercial Computational Fluid Dynamics software to investigate the effects of the direct injection strategy on the combustion and emissions characteristics of a light-duty engine fueled with natural gas and diesel. While considering a split injection strategy for the diesel fuel, a reduction in NOx emissions and controllable $\mathrm{HC}$ and $\mathrm{CO}$ emissions was achieved by increasing the NG fraction and advancing the diesel pilot injection timing, increasing the diesel fuel injection quantity, and lowering the pressure of the first diesel injection.

A typical definition for micro-pilot ignition is where more than $90 \%$ of the net chemical energy is from the premixed NG (i.e., diesel substitution ratio $\geq 90 \%$, Figure 1 ) at all engine operating conditions. This distinction is made because traditional diesel injection systems tend to have degraded spray quality (e.g., penetration, atomization, and mixing) when the pilot quantities are between $10 \%$ and $1 \%$ of the full load quantity. To reliably deliver the low injection quantities that are solely needed to ignite a near-stoichiometric premixed fuel-air mixture, the diesel injection system needs to be reoptimized. Such a fuel system modification would mean that, unlike a traditional dual-fuel engine, a micro-pilot engine is typically restricted from operating in a diesel-only configuration.

While many studies have recently focused on pilot-ignited natural gas engines operated at low loads, only a few focused on micro-pilot ignition [15,17,18]. Jamrozik et al. [16] focused on the effect of an NG substitution ratio from $0 \%$ to $95 \%$. They reported that the increase in NG substitution ratio increases the ignition delay of the diesel pilot and shortens the overall combustion duration. Only one study was found that paired the micro-pilot ignition in a globally stoichiometric mixture [19]. In this work, You et al. discusses the 
dilution effect of inert gases $\left(\mathrm{Ar}, \mathrm{N}_{2}\right.$, and $\left.\mathrm{CO}_{2}\right)$ under low-load stoichiometric conditions on a six-cylinder turbocharged engine. Ar and $\mathrm{N}_{2}$ were shown to boost engine power as the dilution ratio was increased. However, $\mathrm{CO}_{2}$ (generally supplied through exhaust gas recirculation systems) degraded the combustion process, including heat release rate, cylinder peak pressure, and combustion phasing. Because of the lower cylinder temperature, $\mathrm{CO}_{2}$ dilution resulted in the lowest NOx emissions of the three gases tested, while Ar resulted in the greatest NOx emission.

To the best of the authors' knowledge, there is no published research that has investigated the limits of combustion and the minimum stable load that can be maintained at stoichiometric conditions through the optimization of engine hardware (compression ratio), operating condition (EGR, Injection timing), and micro-pilot injection strategy (pressure, quantity). The diesel micro-pilot strategy is an attractive area of study as it aims at minimizing the diesel combustion contribution to GHG emissions while leveraging its high ignition energy potential. Therefore, the purpose of this research is to determine the limits of a natural gas diesel micro-pilot engine's light-load operation and its controlling parameters by optimizing engine hardware, operating conditions, and injection strategies to achieve the lowest possible load while operating in a stoichiometric equivalence ratio and maintaining combustion stability. Furthermore, the TWC requirements for operating the system at low load and the engine out emissions implications of transitioning to lean operation below the minimum NG operating load are also investigated.

This paper is divided into three sections. The experimental apparatus is explained in Section 2, which includes an overview of the modified diesel engine to run micro-pilot diesel natural gas mode, the instrumentation and fuels used, and a description of the test approach. Section 3 centers on presenting engine results and discussing the reported results. The last section concludes this study.

\section{Materials and Methods}

\subsection{Micro-Pilot Diesel Natural Gas Engine}

This section summarizes the engine's major modifications, including compression ratio reduction, fuel, air handling system, and instrumentation. The modifications are described in [22], but the essential features are briefly mentioned here.

A Cummins 6.7 L diesel engine was adapted for this project to run under micropilot diesel and natural gas combustion with a maximum diesel contribution of $10 \%$ of total fuel energy. The approach combines overall stoichiometric combustion consisting primarily of premixed NG with EGR for combustion temperature management and a micro-pilot injection of diesel to offer a reliable ignition source. Stoichiometric operation enables the use of a three-way catalyst to meet emissions criteria. This is a substantial simplification compared to the multi-element aftertreatment systems required to meet emissions standards in modern diesel engines.

For the medium-duty market, a feature of modern NG-fueled on-road engine products is the coupling of stoichiometric combustion with EGR, and with a spark plug to ignite the fuel-air mixture. The method being investigated here uses a very small quantity diesel pilot as the ignition source instead of a spark plug. This strategy provides a more robust ignition, premixed turbulent flame combustion, and shorter distances for the flame to propagate across the combustion chamber by providing higher ignition energy and a more distributed ignition source for the premixed mixture. Compared to premixed SI methods, these effects are expected to lessen the chance for knock, allowing for higher thermal efficiency through a higher compression ratio, better combustion timing, and lower coefficient of variance (COV) of net indicated mean effective pressures (NMEP) and shorter combustion duration.

Converting the engine to a stoichiometric premixed operation resulted in significant changes to the air handling system (shown in Figure 2). A throttle valve was installed downstream of the compressor discharge to manage airflow rate, primarily to maintain stoichiometric mixtures at all loads. A specially constructed mixer system was created to meet the flow requirements for both NG and EGR, with an aim of maximizing the 
uniformity of the premixed fuel-air-EGR mixture being supplied to the intake manifold. A natural gas injector manifold with six prototype high-flow port injectors rated at $8 \mathrm{~g} / \mathrm{s}$ each supplies gaseous fuel to the NG-air-EGR mixer in the mixer system. An airfoil is fitted across the throat of a mixing venturi, with a series of small diameter holes sized to give a suitable pressure drop over the mixer. To allow enough mixing time before the premix mixture is inducted into the engine, the mixer is situated downstream of the throttle but upstream of the intake manifold.

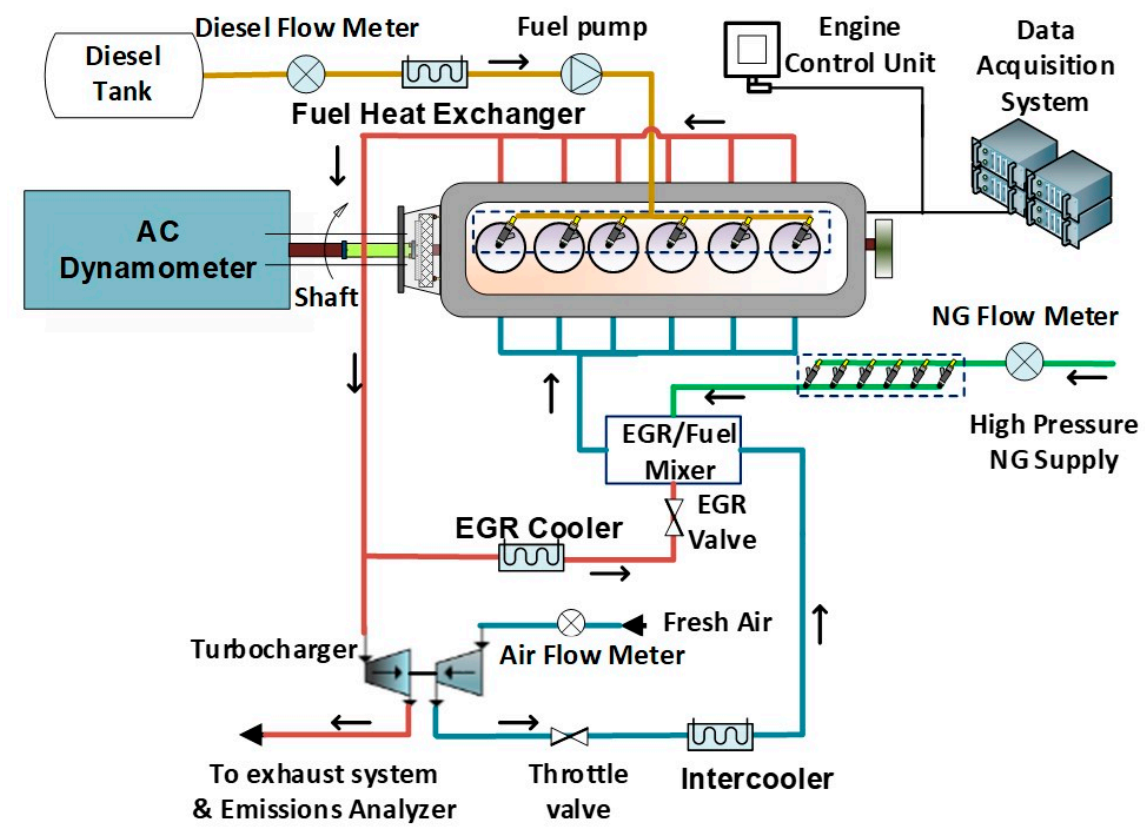

Figure 2. Engine experimental setup.

While this work focuses on low-load operation, a key target for the stoichiometric micro-pilot engine is to achieve a high maximum power (24 bar BMEP). To avoid end gas auto-ignition at high loads, it was necessary to decrease the compression ratio from 17.3 to 15:1. This was achieved through a thicker head gasket and lowering the pistons' top face crown heights by $2.8 \mathrm{~mm}$. Apart from the machining change, the piston bowl geometry remained unchanged from the stock diesel engine configuration.

Table 1 shows the engine's specifications. A MotoHawk ECU565-128 engine controller is utilized in conjunction with a custom-built strategy to manage the engine actuators, including pilot SOI, pilot injection pressure, injection quantity, equivalence ratio, wastegate position, charge air cooling, and dilution.

Table 1. Engine's specifications. HP stands for High Pressure, and VGT stands for Variable Geometry Turbocharger.

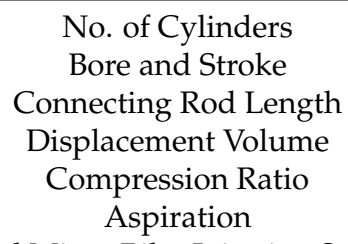

Diesel Micro-Pilot Injection System

Diesel Injection Pressure

Diesel Micro-Pilot Minimum Fuel Quantity

6
$107 \times 124 \mathrm{~mm}$
$192 \mathrm{~mm}$
$6.7 \mathrm{~L}$
$15.0: 1$

Turbocharged (VGT) + Charge Air Cooler + HP EGR + Throttle Valve HPCR injector 8 holes (168 microns diameter) 600 to 2000 bar $3.3 \mathrm{mg}$ /injection 


\subsection{Instrumentation and Measurement Uncertainty}

In-cylinder pressure is measured using AVL GH series piezoelectric pressure transducers installed in each of the engine's six cylinders, feeding a real-time combustion analyzer system. A BEI encoder series H25D with 360 pulses per revolution is used to measure crank angle position in the A\&D CAS system for high-speed combustion analysis. The engine's speed and load are regulated by a $445 \mathrm{hp} \mathrm{AVL} \mathrm{A/C} \mathrm{Dynoroad} \mathrm{308/4} \mathrm{SX} \mathrm{dynamometer.}$

Thermocouple and 0-10 V analog input signals are logged using an NI PCIe chassis. The intake air manifold, engine coolant, engine oil, exhaust gas temperature, turbocharger inlet, and output are equipped with Type $\mathrm{K}$ thermocouples for temperature readings. The MMA050V5P4D1T3A5CE Omega Absolute Pressure Transducer measures the intake and exhaust pressures. The Omega Gage Pressure Transducer GP50 measures other pressures, including oil pressure and fuel input.

The fuel flow rates are measured using two Micro Motion Coriolis Meters ELITE CMFS010P, one for diesel and the other for natural gas. The intake and exhaust $\mathrm{CO}_{2}$ concentrations, used to calculate the EGR rate, are measured using $\mathrm{CO}_{2}$ Meter $\mathrm{K} 33$ series sensors. These are installed in the exhaust and intake manifolds to allow for real-time EGR determination. A Horiba MEXA 1600 emissions bench is used to monitor gaseous emissions. Engine-out emissions were measured using a single analyzer.

Table 2 shows the transducer accuracies and uncertainties for the independent variables based on the information provided by the sensor manufacturers.

Table 2. Instrumentation accuracy and measurement uncertainty. FS stands for Full Scale.

\begin{tabular}{ccccc}
\hline Measurement & Accuracy & Full Scale & Uncertainty (Absolute) & Unit \\
\hline In-Cylinder Pressure Transducer & $\pm 0.30 \% \mathrm{FS}$ & $0-250$ & \pm 0.75 & $\mathrm{bar}$ \\
Engine Crank Angle Degree (Encoder) & \pm 1.00 & $360: 1$ & \pm 1.00 & $\mathrm{D}$ \\
Fuel Flow Rate (Diesel and NG) & $\pm 0.05 \mathrm{FS}$ & $0-30$ & \pm 0.015 & $\mathrm{~g} / \mathrm{s}$ \\
Thermocouples & \pm 2.20 & $0-800$ & \pm 2.20 & ${ }^{\circ} \mathrm{C}$ \\
Intake/Exhaust Manifold Pressure Transducer & $\pm 0.08 \% \mathrm{FS}$ & $0-6.89$ & \pm 0.0055 & $\mathrm{bar}$ \\
Oil and Fuel Inlet Pressure & $\pm 0.50 \% \mathrm{FS}$ & $0-7 / 0-2$ & $\pm 0.035 / 0.010$ & $\mathrm{bar}$ \\
Torque & $\pm 0.05 \% \mathrm{FS}$ & $0-5000$ & \pm 2.50 & $\mathrm{Nm}$ \\
NOx Analyzer & $\pm 1.00 \% \mathrm{FS}$ & $0-5000$ & \pm 50.0 & $\mathrm{ppm}$ \\
THC Analyzer & $\pm 1.00 \% \mathrm{FS}$ & $0-10,000$ & $\mathrm{ppm}$ \\
\hline
\end{tabular}

The uncertainty of the dependent variables in Table 3 is determined using Equation (1) from the uncertainty propagation approach described in [23].

$$
U_{Y}=\sqrt{\sum\left(\frac{\partial Y}{\partial X_{i}}\right)^{2} U_{x}^{2}}
$$

where $Y$ represents the calculated quantity's value, $U$ represents the variable's uncertainty, and $X$ represents the measured variables.

Table 3. Uncertainty propagation to the dependent variables.

\begin{tabular}{cccc}
\hline Measurement & Range & Uncertainty (Absolute) & Unit \\
\hline NMEP & $4.70-8.00$ & \pm 0.15 & $\mathrm{Bar}$ \\
Combustion Stability (COV & $0.40-9.0$ & \pm 0.05 & $\%$ \\
Ignition Delay & $1.70-5.0$ & \pm 0.08 & $\mathrm{~ms}$ \\
Diesel Substitution Ratio & $86.0-93.2$ & \pm 0.50 & $\%$ \\
CA50 & $12.0-32.0$ & \pm 0.60 & ${ }^{\circ} \mathrm{aTDC}$ \\
Exhaust Gas Recirculation & $0.00-12.0$ & \pm 0.20 & $\%$ \\
Equivalence Ratio & $0.80-1.0$ & \pm 0.01 & - \\
BSNOx & $0.20-133$ & \pm 34.1 & $\mathrm{~g} / \mathrm{kWh}$ \\
BSTHC & $2.10-37.0$ & \pm 5.00 & $\mathrm{~g} / \mathrm{kWh}$ \\
\hline
\end{tabular}

${ }^{\circ}$ aTDC stands for Degrees after Top Dead Center. 


\subsection{Fuels}

The fuel qualities and characteristics for both diesel and natural gas are shown in Table 4 . The gas supply company (SEMCO) measured the composition of the natural gas, which reflects an average composition of the gas during the testing program. The main constituents were $89 \% \mathrm{CH}_{4}, 8 \% \mathrm{C}_{2} \mathrm{H}_{6}, 0.4 \% \mathrm{C}_{3} \mathrm{H}_{8}$, and $2.6 \%$ inert (all percent by volume).

Table 4. Fuel Properties. AFR stands for Air Fuel Ratio.

\begin{tabular}{cccccc}
\hline \multirow{2}{*}{ Diesel (ULSD) } & Density $\left(\mathrm{kg} / \mathrm{m}^{3}\right)$ at $15.6^{\circ} \mathrm{C}, 1 \mathrm{~atm}$ & $\begin{array}{c}\text { Lower Heating Value } \\
(\mathrm{MJ} / \mathrm{kg})\end{array}$ & $\begin{array}{c}\text { Stoichiometric } \\
\text { AFR }\end{array}$ & H/C & Cetane Number \\
\cline { 2 - 6 } & 851.6 & 42.8 & 14.60 & 1.85 & 51.7 \\
\hline \multirow{2}{*}{$\mathrm{CNG}$} & Density $\left(\mathrm{kg} / \mathrm{m}^{3}\right)$ at $20^{\circ} \mathrm{C}, 1 \mathrm{~atm}$ & $\begin{array}{c}\text { Lower Heating Value } \\
(\mathrm{MJ} / \mathrm{kg})\end{array}$ & $\begin{array}{c}\text { Stoichiometric } \\
\text { AFR }\end{array}$ & H/C & Methane Number * \\
\cline { 2 - 6 } & 0.727 & 47.5 & 16.30 & 3.80 & 83.0 \\
\hline
\end{tabular}

*Wärtsilä Methane Number Calculator [24].

The Diesel Substitution Ratio (DSR) is calculated on an energy basis in this study, as shown in Equation (2).

$$
D S R=\frac{\dot{m}_{C N G} \cdot Q_{L H V, C N G}}{\dot{m}_{C N G} \cdot Q_{L H V, C N G}+\dot{m}_{\text {Diesel }} \cdot Q_{L H V, \text { Diesel }}}
$$

where, $\dot{m}$ is the fuel mass flow rate in kilograms per second $(\mathrm{kg} / \mathrm{s})$, and $Q_{L H V}$ is the lower heating value of each fuel in MJ $/ \mathrm{kg}$, as described in Table 4 .

The Equivalence Ratio $(\varphi)$ is determined as shown in Equation (3).

$$
\varphi=\frac{\dot{m}_{C N G} \cdot A F R_{\text {stoich }, \mathrm{CNG}}+\dot{m}_{\text {Diesel }} \cdot A F R_{\text {stoich,Diesel }}}{\dot{m}_{\text {air }}}
$$

where AFR is the stoichiometric mass air to fuel ratio of each fuel, as described in Table 4. Equation (3) is based on fresh airflow. As the mixture was stoichiometric, any recirculated exhaust gases had negligible oxygen content and therefore did not impact the global equivalence ratio.

\subsection{Experimental Procedure}

The experimental procedure consisted of varying selected combustion control parameters while keeping all other control parameters constant. The investigated parameters include CA50 (controlled by the diesel pilot SOI), exhaust gas recirculation, diesel pilot injection pressure, and diesel pilot injection quantity. The research team has previously shown that pilot start of injection timing and EGR are the dominant control parameters at medium loads in a stoichiometric micro-pilot engine (Bonfochi Vinhaes et al. [25]). However, for the low-load operation, the engine operating controls are constrained differently than those at medium load. For instance, reducing the intake manifold pressure to reduce load while maintaining a stoichiometric mixture is constrained by the minimum in-cylinder conditions required for pilot ignition and stable combustion. Therefore, the MAP and equivalence ratio are kept at a constant value for all tests in this study. The intake manifold temperature was shown in the prior work to be the least impactful parameter in combustion stability and thus will not be studied in this work.

All tests were performed at 1200 RPM and at a stoichiometric global equivalence ratio, and the intake temperature was kept constant at $35^{\circ} \mathrm{C}$. For the original compression ratio of 17.3:1, the intake manifold pressure of $80 \mathrm{kPa}$ was the minimum throttled value determined in preliminary testing below which the combustion was unstable (instability,

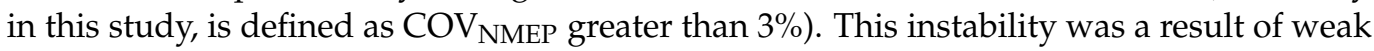
and unstable diesel pilot ignition, resulting from the low in-cylinder pressure and tempera- 
tures under throttled operation. To establish this minimum pressure, an injection timing sweep was conducted to find the minimum combustion variability, and then the intake manifold pressure was gradually reduced by closing the intake throttle. The minimum acceptable pressure was identified as the throttle position before which the combustion became unstable $\left(\mathrm{COV}_{\mathrm{NMEP}}>3 \%\right)$. A further restriction on intake pressure results from the unmodified piston rings and valve stem seals for the diesel-based combustion system. These were not designed for sub-atmospheric intake manifold or in-cylinder pressures, limiting the degree of throttling that could be applied without excessive oil carry-over into the intake ports and cylinders. For the reduced compression ratio (i.e., 15.0), the minimum intake manifold pressure was $85 \mathrm{kPa}$ (absolute).

To study the effect of different compression ratios, the CA50, pilot injection pressure, and EGR sweeps were done with both the stock compression ratio of 17.3:1 and the reduced compression ratio of 15.0:1. The pilot quantity sweep was only performed at the reduced compression ratio of 15.0:1 using the maximum EGR quantity identified in the previous sweep. For every parameter swept, the combustion stability limit was set to $3 \%$ COV of NMEP. Table 5 shows the test conditions summary, including the parameters swept and their range.

Table 5. Experimental test summary.

\begin{tabular}{|c|c|c|c|c|c|c|c|c|c|}
\hline & \multicolumn{9}{|c|}{ Range of Operating Conditions Investigated } \\
\hline & Speed & EQR & MAP & $\begin{array}{l}\text { Intake } \\
\text { Temp. }\end{array}$ & CR & $\begin{array}{l}\text { Diesel Pilot } \\
\text { SOI }\end{array}$ & $\begin{array}{l}\text { Diesel Inj. } \\
\text { Pressure }\end{array}$ & EGR & $\begin{array}{l}\text { Diesel Pilot } \\
\text { Quantity }\end{array}$ \\
\hline & RPM & - & $\mathbf{k P a}$ & ${ }^{\circ} \mathrm{C}$ & - & ${ }^{\circ}$ bTDC & bar & $\%$ & $\mathrm{mg} /$ Injection \\
\hline CA50 Study & \multirow{4}{*}{1200} & \multirow{4}{*}{1.0} & \multirow{4}{*}{$\begin{array}{c}80 \text { (CR17.3); } \\
85 \\
\text { (CR15.0) }\end{array}$} & \multirow{4}{*}{35} & $15.0 ; 17.3$ & 2.0 to 15 & 1000 & 0 & 3.3 \\
\hline $\begin{array}{l}\text { Diesel Inj. Pressure } \\
\text { Study }\end{array}$ & & & & & $15.0 ; 17.3$ & $\begin{array}{l}2.5 \text { (CR17.3); } \\
7.0 \text { (CR15.0) }\end{array}$ & 600 to 1200 & 0 & 3.3 \\
\hline EGR Study & & & & & 15.0 & 7.0 to 15 & 600 & 0 to 12 & 3.3 \\
\hline Pilot quantity Study & & & & & 15.0 & 15 & 600 & 12 & 3.3 to 6.6 \\
\hline
\end{tabular}

\section{Results and Discussion}

\subsection{CA50 Study}

In this study, the combustion phasing was swept by changing the diesel pilot start of injection. The investigation was performed at the original and reduced compression ratio. Figure 3 shows how the engine load, represented by the NMEP, varies as the CA50 is retarded. The minimum stable loads achieved for each compression ratio are highlighted in Figure 3a. These conditions correspond to the maximum combustion stability limit represented by the $\mathrm{COV}_{\text {NMEP }}$ of $3 \%$, as seen in Figure 3b. At the original CR of 17.3:1, the minimum load observed was of 6.5 bar NMEP, while at the reduced CR of 15.0:1 the minimum load observed was 7.2 bar NMEP. These loads correspond to about $30 \%$ of the engine's maximum load.

The load difference of 0.7 bar seen between the original CR and reduced CR is expected due to the higher intake manifold pressure required to operate the engine when at the reduced CR configuration. This is a direct result of the lower end-of-compression temperature with the reduced compression ratio, impacting both diesel pilot ignition and subsequent flame propagation. Interestingly, in Figure $3 a$, both curves show a similar trend as CA50 increases. 
(a)

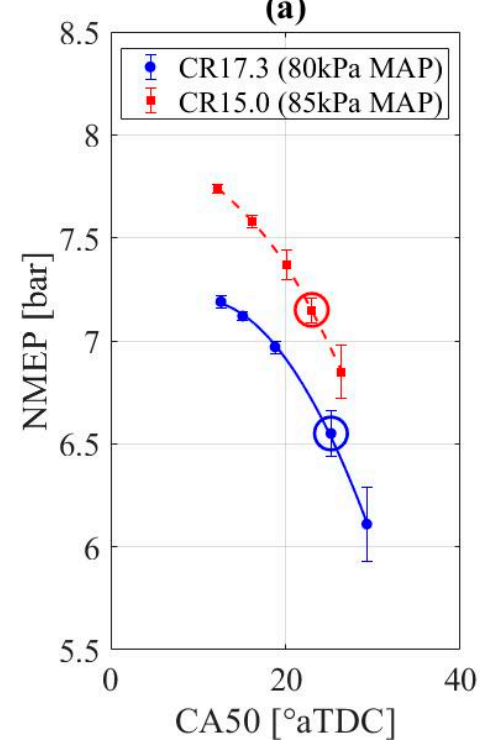

(b)

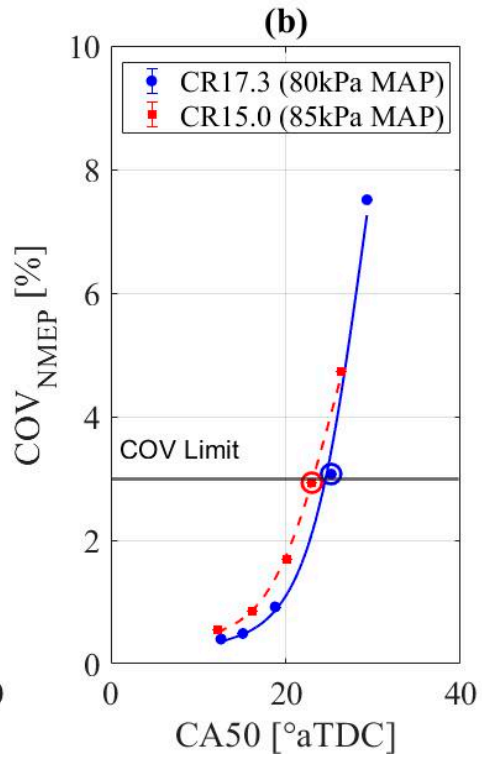

Figure 3. Results for the CA50 sweep test. (a) NMEP vs. CA50. (b) COV NMEP vs. CA50. Engine operating conditions: $80 \mathrm{kPa}$ MAP (for CR17.3) and $85 \mathrm{kPa}$ MAP (for CR15.0); 0\% EGR; $35^{\circ} \mathrm{C}$ IMAT; pilot quantity of $3.3 \mathrm{mg} / \mathrm{inj}$. at 1000 bar inj. pressure; $1200 \mathrm{RPM}$; EQR 1 . The circled data points correspond to the lowest load achieved at the combustion stability limit.

Retarding the combustion phasing is a common strategy utilized in spark-ignition (SI) engines to reduce engine load. The effect of the combustion retard on NMEP is discussed by Heywood et al. [26]. Their work tested the impact of combustion retard over a wide range of spark-ignited operating conditions and collapsed into one universal curve given by Equation (4), where MBT stands for the maximum brake torque. This correlation demonstrates the impact of combustion phasing on the engine load and thermal efficiency. Figure 4 shows the correlation for the effect of combustion retard on the normalized load presented by Heywood.

$$
\frac{N M E P}{N M E P_{M B T}}=1-0.168\left[\left(1+4.443 \times 10^{-3}\left(C A 50-C A 50_{M B T}\right)^{2}\right)^{0.5}-1\right]
$$

It was observed that the micro-pilot natural gas engine trend is similar to that of SI engines and could be approximated by the same correlation with different parameters, shown in Equation (5), with the modification highlighted by the bold number.

$$
\frac{N M E P}{N M E P_{M B T}}=1-\mathbf{0 . 2 1 0}\left[\left(1+4.443 \times 10^{-3}\left(C A 50-C A 50_{M B T}\right)^{2}\right)^{0.5}-1\right]
$$

The difference between these correlations could be explained by the higher heat transfer in the micro-pilot engine caused by the micro-pilot engine's larger combustion chamber volume to surface area ratio compared to the SI engine in [26]. Other potential hypotheses include:

1. The higher compression ratio of the micro-pilot engine vs. the SI engine;

2. Different combustion chamber geometries;

3. Natural gas premix flame speed versus gasoline premix flame speed.

These hypotheses could further be investigated in future work. 


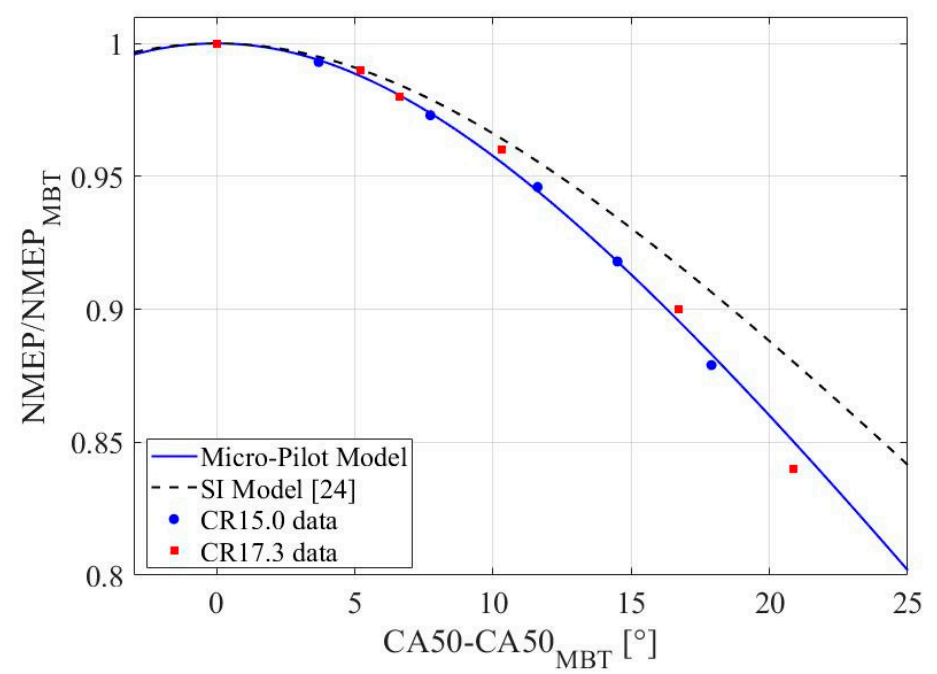

Figure 4. Effect of combustion phasing retard on normalized NMEP. Engine operating conditions: $80 \mathrm{kPa}$ MAP (for CR17.3) and $85 \mathrm{kPa}$ MAP (for CR15.0); $\%$ EGR; $35{ }^{\circ} \mathrm{C}$ IMAT; pilot quantity of $3.3 \mathrm{mg} /$ inj. at 1000 bar inj. Pressure; 1200 RPM; EQR 1.

Figure 4 also shows that, when compared to the SI engine correlation, the micro-pilot engine combustion phasing retard causes a stronger load loss penalty. This shows the importance of the optimum combustion phasing in diesel micro-pilot NG engines.

\subsection{Diesel Injection Pressure Study}

For this study, the pilot diesel injection pressure was swept from 600 bar to 1200 bar in both original and reduced compression ratios while keeping everything else constant. Figure 5 shows how NMEP and the $\mathrm{COV}_{\mathrm{NMEP}}$ vary with the pilot injection pressures while the injection timing is constant. When injection pressure is decreased from 1000 bar to 600 bar, it results in a load increase from 6.5 bar NMEP to 6.8 bar NMEP for the original compression ratio and from 7.2 bar NMEP to 7.5 bar NMEP for the reduced compression ratio. The operation with an injection pressure of 1200 bar resulted in unstable combustion in both CRs.

(a)

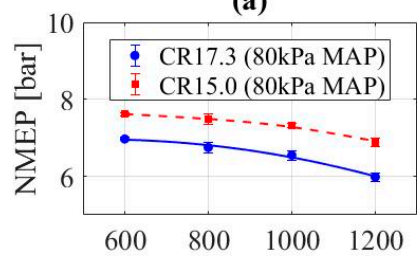

Diesel Pilot Inj. Pressure [bar]

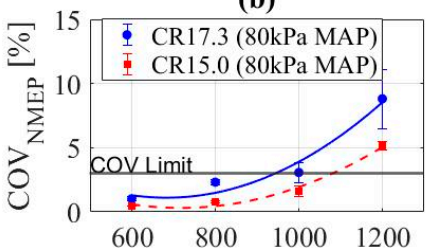

Diesel Pilot Inj. Pressure [bar]

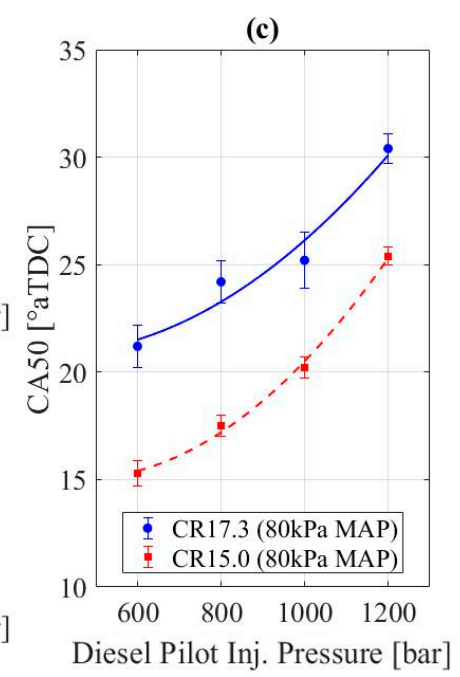

Figure 5. Results for the pilot diesel injection pressure sweep. (a) NMEP vs. Inj. Pressure, (b) $\mathrm{COV}_{\mathrm{NMEP}}$ vs. Inj. Pressure, (c) CA50 vs. Inj. Pressure. Engine operating conditions: $80 \mathrm{kPa}$ MAP (for CR17.3) and $85 \mathrm{kPa}$ MAP (for CR15.0); 0\% EGR; $35^{\circ} \mathrm{C}$ IMAT; Constant diesel pilot SOI; Pilot quantity of $3.3 \mathrm{mg} /$ inj.; $1200 \mathrm{RPM}$; EQR 1. 
The load increase seen by reducing the injection pressure can be attributed to the occurrence of an earlier CA50, as shown in Figure 5c. The CA50 location is observed to be up to 5 degrees earlier in the cycle as injection pressure is changed from 1000 bar to 600 bar. This earlier CA50 may be a result of either a shorter combustion duration and/or an earlier start of combustion. Of these, the average combustion duration was 15 degrees with a standard deviation of only a couple of degrees for all operating conditions of this investigation. In this work, combustion duration is calculated using the integrated heat release rate and is defined as the number of degrees between the crank angle at which $10 \%$ and $90 \%$ of the total energy release has occurred (CA10-90). The ignition delay, however, was reduced by up to $15 \%$ when comparing the operation at 600 bar to the 1000 bar injection pressure for both compression ratios, as shown in Figure 6. Interestingly, the compression ratio did not seem to affect the ignition delay. This could be explained by the difference in MAP and NMEP (i.e., higher load observed in the reduced compression ratio) leading to equivalent in-cylinder pressure and temperature conditions at SOI for both CRs.

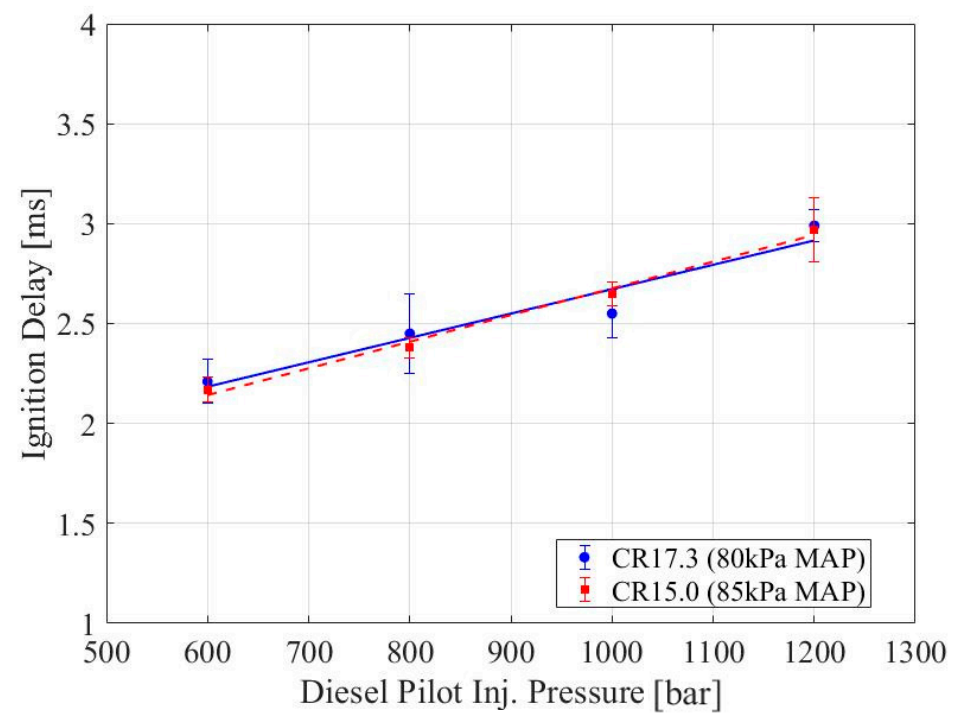

Figure 6. Ignition delay vs. Inj. Pressure. Engine operating conditions: $80 \mathrm{kPa}$ MAP (for CR17.3) and $85 \mathrm{kPa}$ MAP (for CR15.0); 0\% EGR; $35^{\circ} \mathrm{C}$ IMAT; Constant diesel pilot SOI; Pilot quantity of $3.3 \mathrm{mg} / \mathrm{inj}$; $1200 \mathrm{RPM}$; EQR 1. Ignition delay is calculated by the time between the hydraulic start of injection and CA10.

The shorter ignition delay behavior could be due to the shorter diesel pilot penetration due to the lower pressure. This shorter penetration would concentrate the ignition locations nearer the center of the combustion chamber for lower injection pressures, facilitating the initiation of the propagating flame through the premixed natural gas/air mixture. This also agrees with what has been reported by Khosravi et al. [27].

The shorter ignition delay with lower injection pressure increases the NMEP and advances the combustion phasing (Figure 5a,c). By applying the approach discussed for the injection timing study (Figure 3, Section 3.1), the effect of the combustion phasing retard on NMEP can be assessed relative to the to the micro-pilot correlation (i.e., Equation (5)). This is shown in Figure 7; interestingly, the injection pressure study agrees with the model, indicating that the combustion phasing retard, caused by the change in injection pressure, has the same effect on NMEP as the combustion phasing retard caused by the change in pilot SOI. 


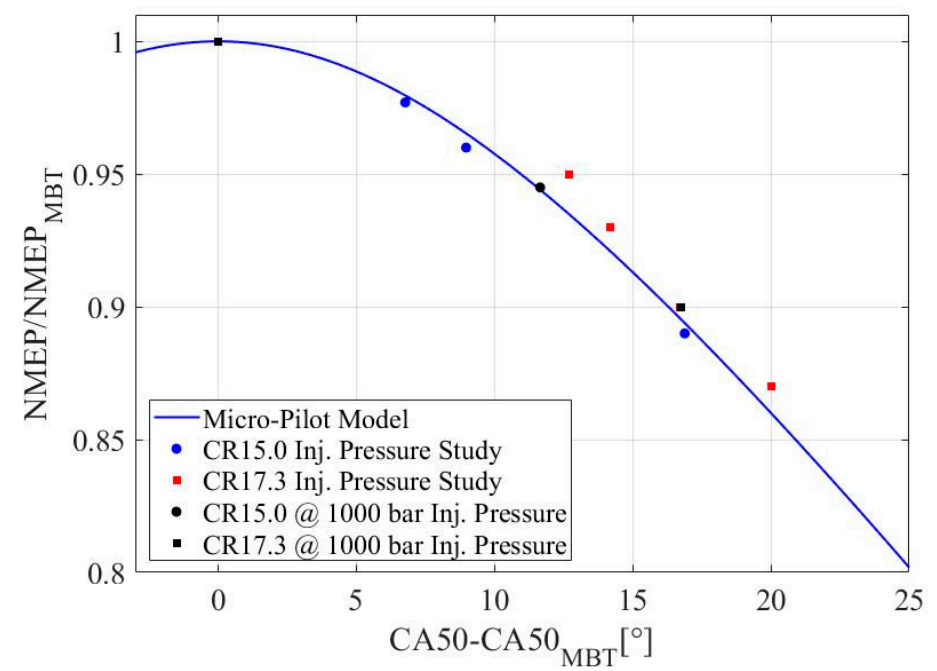

Figure 7. Effect of the pilot injection pressure combustion phasing retard caused by on normalized NMEP. Engine operating conditions: $80 \mathrm{kPa}$ MAP (for CR17.3) and $85 \mathrm{kPa}$ MAP (for CR15.0); 0\% EGR; $35{ }^{\circ} \mathrm{C}$ IMAT; pilot quantity of $3.3 \mathrm{mg}$ /inj; Pilot SOI $2.5^{\circ} \mathrm{bTDC}$ (CR17.3) and Pilot SOI $7.0^{\circ} \mathrm{bTDC}$ (CR15.0); 1200 RPM; EQR 1.

\subsection{EGR Study}

In this section, the results of the EGR study are shown and discussed. Increasing the EGR concentration will reduce the mass of air inducted for a given intake manifold pressure. This will result in a lower total fuel quantity needed to maintain a globally stoichiometric mixture. The process used in this study was to increase the EGR level from the minimum achievable load point at a constant intake manifold pressure. As indicated by Figure 8, the increase in EGR at a constant pilot injection timing results in unstable combustion. The inclusion of EGR increases the specific heat of the premixed charge, resulting in lower in-cylinder temperature; simultaneously, the oxygen content of the intake charge is reduced. These effects lead to a longer ignition delay for the micro-pilot diesel operation. The ignition processes have more time to occur by advancing the diesel injection timing, and combustion stability can be recovered.

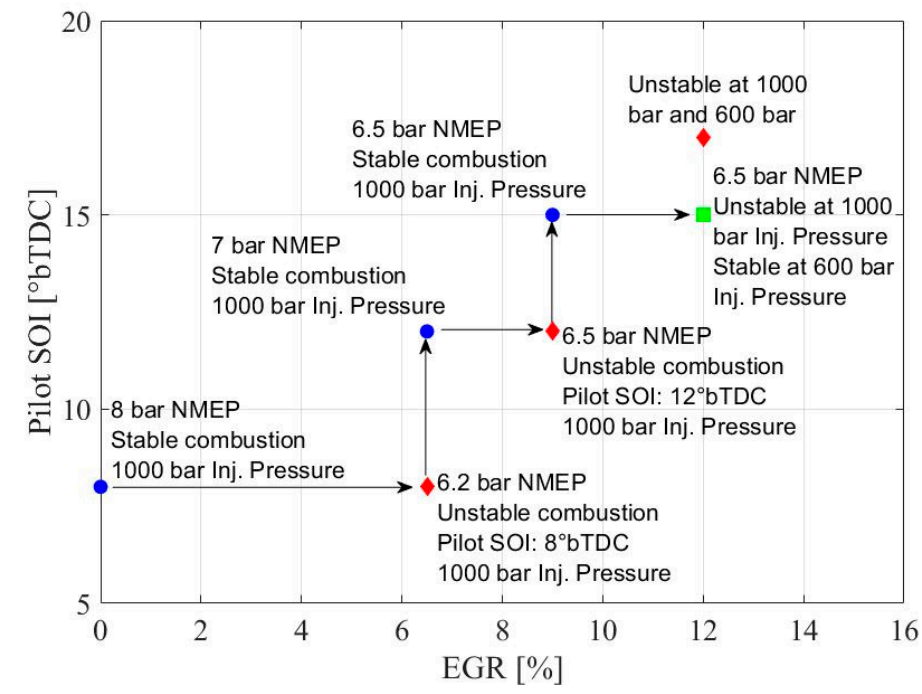

Figure 8. Approach to maintain combustions stability during EGR study by adjusting injection pressure and injection timing. CR 15 Engine operating conditions: $85 \mathrm{kPa}$ MAP; $35^{\circ} \mathrm{C}$ IMAT; Pilot Quantity of $3.3 \mathrm{mg} /$ inj.; 1200 RPM; EQR 1. 
In Figure 8, for the $0 \%$ EGR data point shown at Pilot SOI of $7^{\circ} \mathrm{bTDC}, 8$ bar NMEP with stable combustion at 1000 bar injection pressure (blue circle), EGR was gradually added until $\mathrm{COV}_{\text {NMEP }}$ was greater than $3 \%$, indicating that combustion was unstable (shown in red diamond on Figure 8 at 6.2\% EGR). From there, the EGR quantity was kept at a constant rate while the pilot SOI was advanced until combustion stability was recovered (shown in Figure 8 by the blue circle at $6.2 \%$ EGR at $12^{\circ} \mathrm{bTDC}$ ). This process was repeated until further advancing the pilot SOI did not reduce the $\mathrm{COV}_{\mathrm{NMEP}}$ below 3\%. A maximum level of $9 \%$ EGR was achieved at an SOI limit of $15^{\circ}$ bTDC and injection pressure of 1000 bar. At this point, further advancing SOI showed no effect at regaining stability. The previously observed ignition delay shortening due to lower injection pressure strategy was applied, enabling the maximum EGR level to be increased to $12 \%$. This EGR maximum quantity agrees with a recent study published by You et al. [19] for micro-pilot diesel natural gas engines operating at low loads.

The results in Figure 8 served as a guideline to develop a strategy for achieving lower loads while keeping a globally stoichiometric equivalence ratio. The combination of diluted intake mixture, advanced pilot SOI, and low injection pressure provided the lowest observed load of 6.5 bar NMEP (5.5 bar BMEP).

\subsection{Diesel Pilot Injection Quantity Study}

Lastly, the pilot injection quantity was investigated at the combustion stability limit condition encountered in the EGR study in Section 3.3. The increase in diesel pilot quantity aimed to improve combustion stability by increasing the strength of the ignition source. The investigation was performed only in the reduced compression ratio setup and at the EGR limit of $12 \%$. All operating conditions were kept constant while the pilot quantity was increased from $3.3 \mathrm{mg} / \mathrm{inj}$. to $6.6 \mathrm{mg} / \mathrm{inj}$. Natural gas fueling was reduced to maintain a stoichiometric fuel-air ratio. The total diesel substitution ratio reduces by increasing the diesel pilot quantity, as shown in Figure 9.

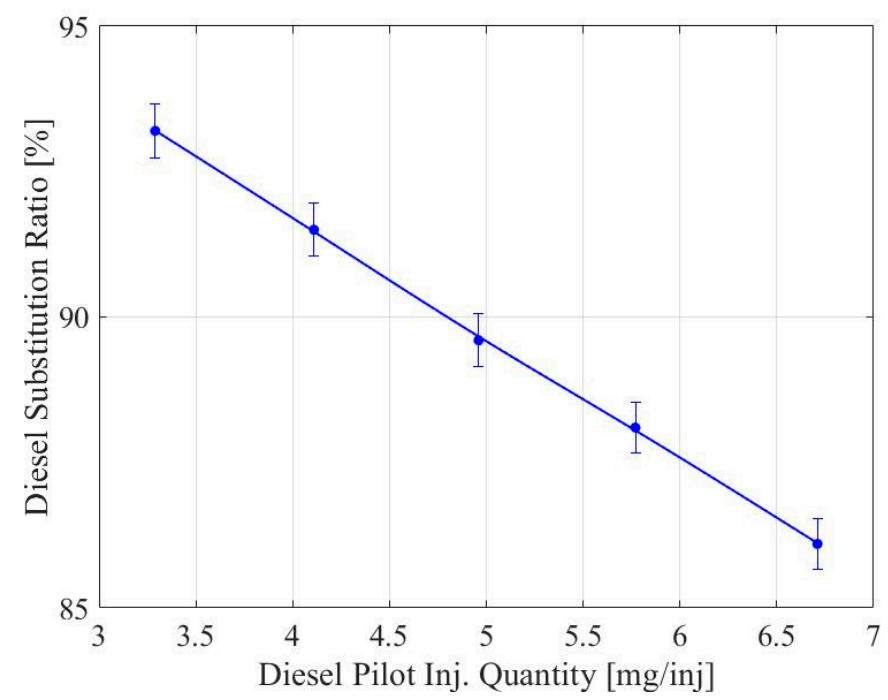

Figure 9. Diesel fuel substitution ratio vs. Inj. Quantity for the operating point at the stability limit with 12\% EGR from Figure 8. CR15 Engine operating conditions: $85 \mathrm{kPa}$ MAP; $35^{\circ} \mathrm{C}$ IMAT; 600 bar Injection Pressure; Diesel Pilot SOI 15bTDC; 1200 RPM; EQR 1; 12\% EGR.

At the minimum injection quantity, the combustion stability is borderline with a $\mathrm{COV}_{\text {NMEP }}$ slightly above $3 \%$ (shown in Figure 10b) and the lowest achieved load output. Increasing the pilot quantity improves combustion stability and leads to a small increase in NMEP. To maintain the pilot quantity below the targeted $10 \%$ of total energy a maximum diesel injection of $4.11 \mathrm{mg} /$ injection is permitted; this results in improved stability and a small load increase of 0.2 bar NMEP. 
(a)

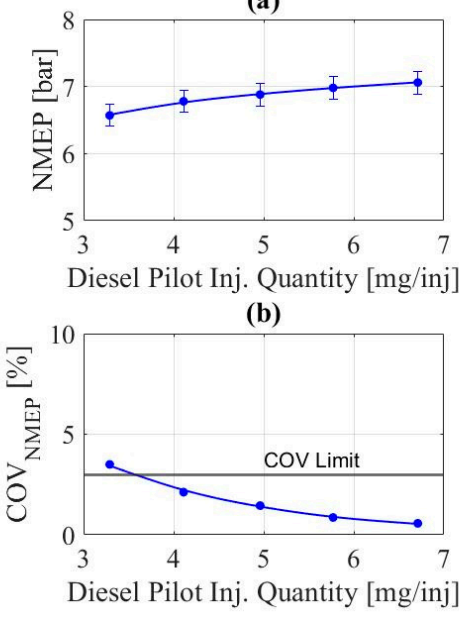

(c)

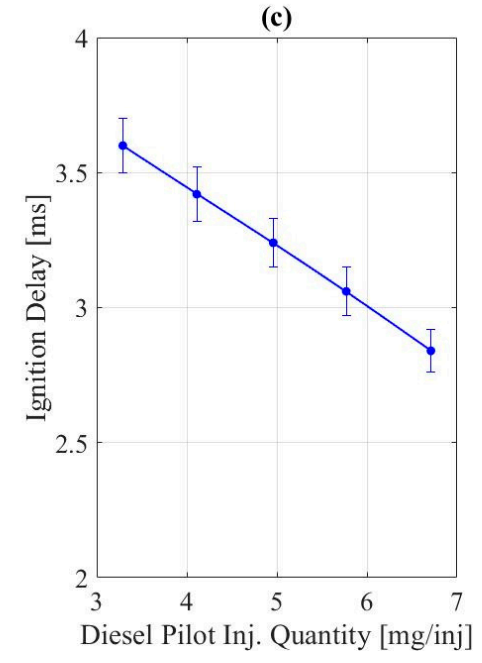

Figure 10. Diesel pilot injection quantity sweep results. (a) NMEP vs. Inj. Quantity (b) $\mathrm{COV}_{\mathrm{NMEP}}$ vs. Injection Quantity (c) Ignition Delay vs. Inj. Quantity. CR15 Engine operating conditions: $85 \mathrm{kPa}$ MAP; $35^{\circ} \mathrm{C}$ IMAT; 600 bar Injection Pressure; Diesel Pilot SOI $15^{\circ} \mathrm{bTDC} ; 1200$ RPM; EQR 1; $12 \%$ EGR.

The changes in load and $\mathrm{COV}_{\mathrm{NMEP}}$ are shown in Figure 10a,b, respectively. As expected, when more diesel fuel is added, the $\mathrm{COV}_{\mathrm{NMEP}}$ reduces as more pilot fuel is available to initiate and maintain the combustion through the premixed charge. With the increase in pilot quantity, the load also increased due to the earlier combustion phasing resulting from, the shorter ignition delay shown in Figure 10c. These results agree well with the previous studies that have shown a similar sensitivity to the pilot quantity, albeit in globally lean conditions [28-31].

Optimizing the SOI timing, EGR level, and injection pressure at higher pilot quantity conditions could result in a small further reduction in NMEP. However, the results from the current study indicate that only incremental reductions in NMEP will be achievable through this optimization. The low in-cylinder temperature and lack of available oxygen and reactive species, due to the presence of both premixed NG and EGR, pose a fundamental limit to achieving robust and stable diesel pilot ignition at very low-load engine conditions.

\subsection{Lowest Stable Load Achievable in Stoichiometric Operation}

By combining the results from investigations in Sections 3.1-3.4, the lowest load achieved while operating stoichiometric was 6.20 bar NMEP at the reduced compression ratio (CR 15.0) and 5 bar NMEP at the original compression ratio (CR 17.3). Table 6 summarizes the minimum low-load operating conditions achieved for the micro-pilot natural gas engine while maintaining a stoichiometric $\mathrm{EQR}$ and stable combustion.

To reduce the minimum load, it is necessary to reduce the fuel quantity without further reducing the in-cylinder end-of-compression temperature. This can be achieved by transitioning from stoichiometric to lean operation. Reducing the EQR from 1 to 0.83 enabled the minimum load to be reduced by $12 \%$ (Figure 11a) with the tradeoff of increase in engine-out unburned HC (THC) by $160 \%$ (Figure 11d). At this condition, the engine-out NOx emission was also observed to be increased by $40 \%$ (Figure 11c). 
Table 6. Minimum load achieved at the stoichiometric operation.

\begin{tabular}{ccc}
\hline & Reduced Compression Ratio (15.0) & Original Compression Ratio (17.3) \\
\hline Load (NMEP) [bar] & 6.20 & 5.20 \\
Indicated Fuel Conversion Efficiency [\%] & 35.7 & 36.3 \\
Diesel Substitution Ratio [\%] & 93.2 & 91.0 \\
Equivalence Ratio [-] & 1.00 & 1.00 \\
EGR [\%] & 12.0 & 12.0 \\
Pilot Injection Pressure [bar] & 600 & 600 \\
Pilot Injection Quantity [mg/inj] & 3.30 & 3.30 \\
CA50 [ ${ }^{\circ}$ aTDC] & 26.0 & 24.0 \\
COV NMEP [\%] & 3.50 & 3.30 \\
MAP [kPa] & 85.0 & 80.0 \\
EGT [ ${ }^{\circ} \mathrm{C}$ ] & 35.0 & 35.0 \\
Intake Manifold Temperature [ $\left.{ }^{\circ} \mathrm{C}\right]$ & 587 & 515 \\
Brake Specific NOx [g/kWh] & 0.50 & 0.25 \\
Brake Specific CO 2 [g/ $/ \mathrm{kWh}]$ & 590 & 538 \\
Brake Specific THC [g/kWh] & 4.20 & 8.90 \\
\hline
\end{tabular}

${ }^{\circ}$ aTDC stands for Degrees after Top Dead Center.

(a)

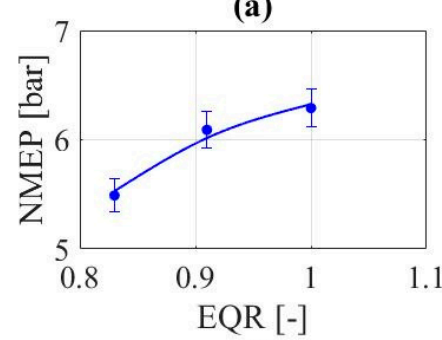

(b)

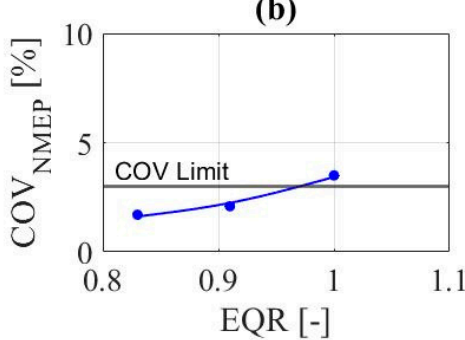

(c)

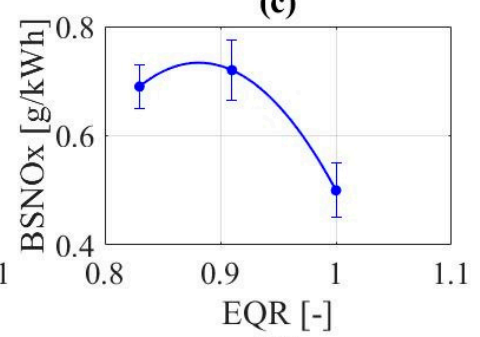

(d)

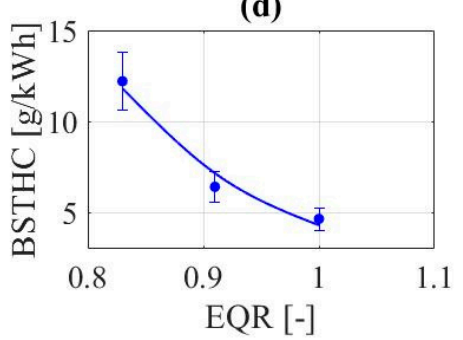

Figure 11. Lean operation impacts on load, stability, and engine out emissions. (a) EQR vs. NMEP. (b) EQR vs. COV NMEP. (c) EQR vs. Brake Specific NOx (BSNOx). (d) EQR vs. Brake Specific THC (BSTHC). CR 15.0; 85 kPa MAP; $35^{\circ} \mathrm{C}$ IMAT; 600 bar Injection Pressure; Diesel Pilot SOI $15^{\circ}$ bTDC; 1200 RPM; Pilot Quantity 3.3 mg/inj.; 12\% EGR.

The increase in unburned HC and NOx shown in Figure 11 agrees with the literature [32] and makes this strategy undesirable because a traditional TWC aftertreatment system would not be able to reduce NOx emissions in an oxygen-rich exhaust stream. As such, a lean NOx trap or another aftertreatment approach would be needed. Furthermore, the TWC enabled through stoichiometric operation can effectively control $\mathrm{CH}_{4}$ emissions at operating temperatures as low as $420{ }^{\circ} \mathrm{C}$ [33]. However, the effectiveness of these systems for unburned methane control, which is the predominant component of the THC emissions, under lean conditions is uncertain. In all studies performed in this work, the lowest and the highest post-turbine exhaust gas temperature observed were $523{ }^{\circ} \mathrm{C}$ and $726{ }^{\circ} \mathrm{C}$, respectively, confirming that a TWC could be applied to effectively control $\mathrm{CO}, \mathrm{NOx}$, and $\mathrm{CH}_{4}$ emissions under stoichiometric conditions. Preliminary testing with a custom TWC system demonstrated $>95 \%$ reductions in all criteria pollutants and $\mathrm{CH}_{4}$ under stoichiometric conditions. Further development of the engine air handling and fueling control systems are needed to ensure robust, low-emission operation over a wider range of steady-state and transient operating conditions. 


\section{Summary and Conclusions}

In summary, this work focused on studying the limits of the low-load operation of a micro-pilot diesel natural gas engine and the effect of controlling parameters including engine hardware by reducing compression ratio and finding the optimum operating condition by sweeping the diesel pilot start of injection and dilution with cooled EGR, as well as adjusting the pilot injection strategy by sweeping injection pressure and injection quantity. These factors were independently investigated with the goal of reaching the minimum load limit while being constrained by the need to operate at stoichiometric equivalence ratio, minimum intake manifold pressure, and having stable combustion.

The key conclusions from this work for the tested engine conditions are:

1. The compression ratio impacts the minimum intake manifold pressure that maintains combustion stable. By reducing the compression ratio from 17.3:1 to 15.0:1, the intake manifold pressure had to be increased by $5 \mathrm{kPa}$, which raised the lowest load achievable by 1 bar NMEP due to the extra premix fuel required to maintain a globally stoichiometric premix.

2. Combustion phasing retard controlled by the diesel micro-pilot start of injection is a way to achieve lower loads. This is a common strategy utilized in spark-ignited engines. A modified version of the correlation for SI engines is proposed in this work to fit the diesel micro-pilot natural gas combustion system. The micro-pilot engine combustion phasing retard has a slightly stronger impact on the minimum possible load than an SI engine. This shows the importance of the optimum combustion phasing in diesel micro-pilot NG engines.

3. The reduction of pilot injection pressure improves combustion stability by the observed shortening of ignition delay. The lower injection pressure helps keep the pilot fuelrich zones near the injector tip, facilitating the flame to initiate and spread inside the combustion chamber. The combustion phasing retard caused by the change in injection pressure agrees with the micro-pilot correlation, indicating that the change in injection pressure does not affect the negative impact of combustion phasing retard on NMEP.

4. The effect of diesel injection pressure was observed to be more dominant in low in-cylinder temperatures (i.e., $\mathrm{T}<900 \mathrm{~K}$ ). This is an important finding to help the development of low-temperature combustion strategies. As the in-cylinder charge temperature is near the diesel auto-ignition limit, the lower injection pressure can improve flame development and combustion stability. This effect becomes negligible as the in-cylinder temperature increases.

5. Adding exhaust gas to the intake can reduce the total fuel ingested while maintaining a stoichiometric mixture, leading to longer diesel pilot ignition delays. The exhaust gas recirculation limit at low load was observed to be $12 \%$ as increasing delay in ignition results in unstable combustion beyond this limit, independent of injection pressure and timing.

6. Increasing the diesel pilot quantity can improve the combustion stability at a given operating condition by providing a robust and stable ignition source. This comes at the cost of reducing the total diesel substitution ratio.

7. Lean operations enabled lower loads by reducing the total fuel quantity in the intake premix for a given intake pressure. Lean operation increased NOx and unburned hydrocarbon emissions by $40 \%$ and $160 \%$, respectively, while lean operation precludes using a TWC to control NOx emissions.

Author Contributions: Formal analysis, V.B.V.; Investigation, V.B.V.; Methodology, V.B.V.; Project Administration, G.M.-C. and J.D.N.; Supervision, G.M.-C., S.M., M.S. and J.D.N.; Writing-Original Draft, V.B.V.; Writing-Review and Editing, G.M.-C., S.M., M.S. and J.D.N. All authors have read and agreed to the published version of the manuscript. 
Funding: This work was financially supported by the Office of Efficiency and Renewable Energy, National Energy Tech Lab (NETL), a subunit of the U.S. Department of Energy under award number DE-EE0007331. Westport Fuel Systems has served as an important industry partner on this project and provided funding under contract number 1601045.

Institutional Review Board Statement: Not Applicable.

Informed Consent Statement: Not Applicable.

Data Availability Statement: Not Applicable.

Acknowledgments: The experimental work was performed at the Advanced Power Systems Laboratories, Michigan Technological University, with the assistance and advice of co-workers: Paul Dice and Joel Duncan. We would also like to thank Jim Huang and Marco Turcios from the Westport Fuel Systems research team for the technical and discussions provided in the development of the process presented in this work.

Conflicts of Interest: The authors declare no conflict of interest.

\section{Nomenclature}

\begin{tabular}{|c|c|c|c|}
\hline AFR & Air to Fuel Ratio & LHV & Lower Heating Value \\
\hline BMEP & Brake Mean Effective Pressure & IMEP & Indicated Mean Effective Pressure \\
\hline BSNOx & Brake Specific NOx & MAP & Manifold Air Pressure \\
\hline BSTHC & Brake Specific THC & MBT & Maximum Brake Torque \\
\hline CA50 & $\begin{array}{l}\text { Crank Angle position at which } 50 \% \text { of the } \\
\text { heat from combustion has been released }\end{array}$ & NG & Natural Gas \\
\hline $\mathrm{CO}$ & Carbon Monoxide & NMEP & Net Mean Effective Pressure \\
\hline $\mathrm{COV}$ & Coefficient of Variance & NOx & Oxides of Nitrogen \\
\hline CR & Compression Ratio & $\mathbf{P}$ & Pressure \\
\hline DSR & Diesel Substitution Ratio & SI & Spark-Ignition \\
\hline EGR & Exhaust Gas Recirculation & SOC & Start of Combustion \\
\hline EQR & Equivalence Ratio & SOI & Start of Injection \\
\hline FS & Full Scale & $\mathbf{T}$ & Temperature \\
\hline GHG & Green House Gases & THC & Total unburned Hydrocarbons \\
\hline HP & High Pressure & TWC & Three-Way-Catalyst \\
\hline ICE & Internal Combustion Engine & VGT & Variable Geometry Turbocharger \\
\hline IMAT & Intake Manifold Air Temperature & & \\
\hline
\end{tabular}

\section{References}

1. Reitz, R.D.; Ogawa, H.; Payri, R.; Fansler, T.; Kokjohn, S.; Moriyoshi, Y.; Agarwal, A.; Arcoumanis, D.; Assanis, D.; Bae, C.; et al. IJER editorial: The future of the internal combustion engine. Int. J. Engine Res. 2020, 21, 3-10. [CrossRef]

2. Karim, G.A. Dual-Fuel Diesel Engines; CRC Press: Boca Raton, FL, USA, 2015; Chapters: 3, 5, and 6. [CrossRef]

3. Manns, H.J.; Brauer, M.; Dyja, H.; Beier, H.; Lasch, A. Diesel CNG—The Potential of a Dual Fuel Combustion Concept for Lower CO 2 and Emissions; SAE2015-26-0048; SAE International: Warrendale, PA, USA, 2015.

4. Karim, G.A. Combustion in Gas Fueled Compression: Ignition Engines of the Dual Fuel Type. J. Eng. Gas Turbines Power 2003, 125, 827-836. [CrossRef]

5. Weaver, C.S.; Turner, S.H. Dual Fuel Natural Gas/Diesel Engines: Technology, Performance, and Emissions; SAE International: Warrendale, PA, USA, 1994. [CrossRef]

6. Daisho, Y.; Yaeo, T.; Koseki, T.; Saito, T.; Kihara, R.; Quiros, E.N. Combustion and Exhaust Emissions in a Direct-Injection Diesel Engine Dual-Fueled with Natural Gas; SAE950465; SAE International: Warrendale, PA, USA, 1995. [CrossRef]

7. Vávra, J.; Bortel, I.; Takáts, M.; Diviš, M. Emissions and performance of diesel-natural gas dual-fuel engine operated with stoichiometric mixture. Fuel 2017, 208, 722-733. [CrossRef]

8. Zheng, J.; Wang, J.; Zhao, Z.; Wang, D.; Huang, Z. Effect of equivalence ratio on combustion and emissions of a dual-fuel natural gas engine ignited with diesel. Appl. Therm. Eng. 2019, 146, 738-751. [CrossRef]

9. Yousefi, A.; Birouk, M.; Guo, H. An experimental and numerical study of the effect of diesel injection timing on natural gas/diesel dual-fuel combustion at low load. Fuel 2017, 203, 642-657. [CrossRef]

10. Zhou, H.; Zhao, H.-W.; Huang, Y.-P.; Wei, J.-H.; Peng, Y.-H. Effects of Injection Timing on Combustion and Emission Performance of Dual-Fuel Diesel Engine under Low to Medium Load Conditions. Energies 2019, 12, 2349. [CrossRef]

11. Valladolid, P.G.; Tunestal, P. Effects of Intake Manifold Conditions on Dual-Fuel CNG-Diesel Combustion in a Light Duty Diesel Engine Operated at Low Loads; SAE2016-01-0805; SAE International: Warrendale, PA, USA, 2016. [CrossRef] 
12. Guo, H.; Neill, W.S.; Liko, B. An Experimental Investigation on the Combustion and Emissions Performance of a Natural Gas-Diesel Dual Fuel Engine at Low and Medium Loads. In Proceedings of the ASME 2015 Internal Combustion Engine Division Fall Technical Conference, American Society of Mechanical Engineers, Houston, TX, USA, 8-11 November 2015. [CrossRef]

13. Papagiannakis, R.G.; Hountalas, D.T. Combustion and exhaust emission characteristics of a dual fuel compression ignition engine operated with pilot diesel fuel and natural gas. Energy Convers. Manag. 2004, 45, 2971-2987. [CrossRef]

14. Taniguchi, S.; Masubuchi, M.; Kitano, K.; Mogi, K. Feasibility Study of Exhaust Emissions in a Natural Gas Diesel Dual Fuel (DDF) Engine; SAE2012-01-1649; SAE International: Warrendale, PA, USA, 2012. [CrossRef]

15. Liu, J.; Guo, Q.; Guo, J.; Wang, F. Optimization of a diesel/natural gas dual fuel engine under different diesel substitution ratios. Fuel 2021, 305, 121522. [CrossRef]

16. Jamrozik, A.; Tutak, W.; Grab-Rogaliński, K. An Experimental Study on the Performance and Emission of the diesel/CNG Dual-Fuel Combustion Mode in a Stationary CI Engine. Energies 2019, 12, 3857. [CrossRef]

17. Wang, Z.; Zhao, Z.; Wang, D.; Tan, M.; Han, Y.; Liu, Z.; Dou, H. Impact of pilot diesel ignition mode on combustion and emissions characteristics of a diesel/natural gas dual fuel heavy-duty engine. Fuel 2016, 167, 248-256. [CrossRef]

18. Dronniou, N.; Kashdan, J.; Lecointe, B.; Sauve, K.; Soleri, D. Optical Investigation of Dual-fuel CNG/Diesel Combustion Strategies to Reduce CO2 Emissions. SAE Int. J. Engines 2014, 7, 873-887. [CrossRef]

19. You, J.; Liu, Z.; Wang, Z.; Wang, D.; Xu, Y. Experimental analysis of inert gases in EGR on engine power and combustion characteristics in a stoichiometric dual fuel heavy-duty natural gas engine ignited with diesel. Appl. Therm. Eng. 2020, 180, 115860. [CrossRef]

20. Papagiannakis, R.G.; Hountalas, D.T.; Rakopoulos, C.D.; Rakopoulos, D.C. Combustion and Performance Characteristics of a DI Diesel Engine Operating from Low to High Natural Gas Supplement Ratios at Various Operating Conditions; SAE2008-01-1392; SAE International: Warrendale, PA, USA, 2008. [CrossRef]

21. Poorghasemi, K.; Saray, R.K.; Ansari, E.; Irdmousa, B.K.; Shahbakhti, M.; Naber, J.D. Effect of diesel injection strategies on natural gas/diesel RCCI combustion characteristics in a light duty diesel engine. Appl. Energy 2017, 199, 430-446. [CrossRef]

22. Naber, J.D.; Henes, R.; Henes, E. High BMEP and High Efficiency Micro-Pilot Ignition Natural Gas Engine (Final Project Report); Office of Scientific and Technical Information (OSTI): Oak Ridge, TN, USA, 2020. [CrossRef]

23. Taylor, B.N. Guidelines for evaluating and expressing the uncertainty of NIST measurement results. In Guidelines for Evaluating and Expressing the Uncertainty of NIST Measurement Results; National Institute of Standards and Technology: Gaithersburg, MD, USA, 1994. [CrossRef]

24. Wärtsilä Methane Number Calculator. 2021. Available online: https://www.wartsila.com/marine/build/gas-solutions/ methane-number-calculator (accessed on 6 September 2021).

25. Bonfochi Vinhaes, V.; Yang, X.; Eggart, B.; McTaggart-Cowan, G.; Munshi, S.; Naber, J.; Shahbakhti, M. Multi-Variable Sensitivity Analysis and Ranking of Control Factors Impact in a Stoichiometric Micro-Pilot Natural Gas Engine at Medium Loads. In Proceedings of the 2022 SAE World Congress, Detroit, MI, USA, 5-7 April 2022.

26. Ayala, F.A.; Gerty, M.D.; Heywood, J.B. Effects of Combustion Phasing, Relative Air-Fuel Ratio, Compression Ratio, and Load on SI Engine Efficiency; SAE2006-01-0229; SAE International: Warrendale, PA, USA, 2006; pp. 177-195. [CrossRef]

27. Khosravi, M.; Rochussen, J.; Yeo, J.; Kirchen, P.; McTaggart-Cowan, G.; Wu, N. Effect of Fueling Control Parameters on Combustion Characteristics of Diesel-Ignited Natural Gas Dual-Fuel Combustion in an Optical Engine. In Proceedings of the ASME 2016 Internal Combustion Engine Division Fall Technical Conference, Greenville, SC, USA, 9-12 October 2016. [CrossRef]

28. Alla, G.H.A.; Soliman, H.A.; Badr, O.A.; Rabbo, M.F.A. Effect of Pilot Fuel Quantity on the Performance of a Dual Fuel Engine; SAE1999-01-3597; SAE International: Warrendale, PA, USA, 1999. [CrossRef]

29. Liu, J.; Yang, F.; Wang, H.; Ouyang, M.; Hao, S. Effects of pilot fuel quantity on the emissions characteristics of a CNG/diesel dual fuel engine with optimized pilot injection timing. Appl. Energy 2013, 110, 201-206. [CrossRef]

30. Papagiannakis, R.; Hountalas, D.; Rakopoulos, C. Theoretical study of the effects of pilot fuel quantity and its injection timing on the performance and emissions of a dual fuel diesel engine. Energy Convers. Manag. 2007, 48, 2951-2961. [CrossRef]

31. Zirngibl, S.; Wachtmeister, G. Extensive Investigation of a Common Rail Diesel Injector Regarding Injection Characteristics and the Resulting Influences on the Dual Fuel Pilot Injection Combustion Process; SAE2016-01-0780; SAE International: Warrendale, PA, USA, 2016. [CrossRef]

32. Heywood, J.B. Internal Combustion Engine Fundamentals; McGraw-Hill Education: New York, NY, USA, 2018; Chapters: 4 and 11; ISBN 1260116107.

33. Smith, I.; Chiu, J.; Bartley, G.; Jimenez, E.; Briggs, T.; Sharp, C. Achieving Fast Catalyst Light-Off from a Heavy-Duty Stoichiometric Natural Gas Engine Capable of $0.02 \mathrm{~g} / \mathrm{bhp}-\mathrm{hr}$ NOx Emissions; SAE2018-01-1136; SAE International: Warrendale, PA, USA, 2018. [CrossRef] 